\title{
Influence of Deformation on the Structure and Mechanical and Corrosion Properties of High-Nitrogen Austenitic 07Kh16AG13M3 Steel
}

\author{
V. V. Berezovskaya, M. S. Khadyev, E. A. Merkushkin, and Yu. A. Sokolovskaya \\ Ural Federal University, ul. Mira 19, Yekaterinburg, 620002 Russia \\ e-mail:v.v.berezovskaya@urfu.ru \\ Received February 7, 2013
}

\begin{abstract}
The correlation has been studied between the structure of a high-nitrogen austenitic $\mathrm{Cr}-\mathrm{Mn}-\mathrm{N}$ steel formed in the process of combined hardening treatment, including cold plastic deformation (CPD), and its mechanical and corrosion properties. The structure and properties of commercial high-nitrogen $(0.8 \% \mathrm{~N})$ 07Kh16AG13M3 steel is analyzed after rolling by CPD and aging at 500 and $800^{\circ} \mathrm{C}$. It is shown that CPD of the steel occurs by dislocation slip and deformation twinning. Deformation twinning and also high resistance of austenite to martensitic transformations at true strains of 0.2 and 0.4 determine the high plasticity of the steel. The contribution of the structure imperfection parameters to the broadening of the austenite lines during CPD is estimated by $\mathrm{X}$-ray diffraction. The main hardening factor is stated to be lattice microdistortions. Transmission electron microscopy study shows that heating of the deformed steel to $500^{\circ} \mathrm{C}$ leads to the formation of the intermediate $\mathrm{CrN}$ phase by a homogeneous mechanism, and the intermtallic $\chi$ phase forms along the austenite grain boundaries in the case of heating at $800^{\circ} \mathrm{C}$. After hardening by all investigated technological schemes, exception for aging at $800^{\circ} \mathrm{C}$, the steel does not undergo pitting corrosion and is slightly prone to a stress corrosion cracking during static bending tests, while aging at $800^{\circ} \mathrm{C}$ causes pitting corrosion at a pitting formation potential $E_{\mathrm{pf}}=-0.25 \mathrm{~V}$.
\end{abstract}

DOI: $10.1134 / \mathrm{S} 0036029513110049$

\section{INTRODUCTION}

In recent years, the development of nitrogen steel metallurgy is due to strong austenite-forming nitrogen property [1]. Nitrogen-alloyed steels are divided into the following two categories: steels with a subequilibrium nitrogen content (these steels are produced by melting and solidification at atmospheric pressure) and steels with an overequilibrium nitrogen content (they are produced at a higher nitrogen pressure). Because of the complexity of electroslag remelting under a nitrogen pressure, high-nitrogen steels are not widely used, although many problems of modern engineering are solved on the basis of their application [2]. High-nitrogen steels are promising due to an unique combination of their high strength, ductility, corrosion resistance, and other properties. It was shown, using binary $\mathrm{Fe}-\mathrm{N}$ solid solutions as an example [1], that the short-range order induced by nitrogen is the cause of their high thermodynamic stability, which is observed in multicomponent austenite steels based on this system [2] and is reflected in the equilibrium phase diagrams of various alloying systems with nitrogen $[3,4]$. In practice, it makes it possible to obtain austenite in the $\mathrm{Fe}-\mathrm{Cr}-\mathrm{N}$ system and more complex systems as a result of quenching from high temperatures at higher chromium content than that in the $\mathrm{Fe}-\mathrm{Cr}-\mathrm{Ni}$ system and to develop nonmagnetic materials with a high corrosion resistance and strength at room and higher temperatures.

When developing carbon-free chromium steels alloyed with $\geq 1 \% \mathrm{~N}$, it is possible to obtain a singlephase structure of supersaturated $\gamma$ solid solution with high strength and corrosion properties in them; however, the steels can demonstrate embrittlement and a tendency toward stress corrosion cracking (SCC) in some structural states caused by austenite decomposition [5]. One of the methods for preventing embrittlement is alloying of high-nitrogen steels with manganese and designing nickel-free $\mathrm{Cr}-\mathrm{Mn}-\mathrm{N}$ steels, which have a strength competitive with that of $\mathrm{Cr}-\mathrm{N}$ steels and surpass them in plasticity and fracture toughness [6]. In addition, one of the substantial advantages of austenite manganese-containing high-nitrogen steels is their ability to significant strain hardening, which increases with the nitrogen content in steel [7]. The use of combined hardening treatment, including heat treatment (HT) and cold plastic deformation (CPD), provides not only additional hardening of high-nitrogen $\mathrm{Cr}-$ $\mathrm{Mn}-\mathrm{N}$ steels but also specific functional properties relative to pitting corrosion and stress corrosion cracking (SCC) [8]. As a result of the combined treatment, high-nitrogen steels can form structures that are insufficiently described in literature or belong to other alloying systems [9]. At the same time, the regularities 
Table 1. Effect of the scheme of hardening treatment and a corrosion medium on the mechanical properties of $07 \mathrm{Kh} 16 \mathrm{AG} 13 \mathrm{M} 3$ steel during concentrated bending tests at a strain rate of $1.5 \times 10^{-3}$ (numerator) and $0.15 \times 10^{-3} \mathrm{~s}^{-1}$ (denominator)

\begin{tabular}{|c|c|c|}
\hline \multirow[b]{2}{*}{ Characteristic } & \multicolumn{2}{|c|}{ Value of characteristic after treatment } \\
\hline & IT & $\begin{array}{c}\mathrm{IT}+\mathrm{CPD} \\
(e=0.2)\end{array}$ \\
\hline \multicolumn{3}{|c|}{ Tests in air } \\
\hline$\sigma_{\mathrm{u}}, \mathrm{MPa}$ & $2220 / 2320$ & $2540 / 2680$ \\
\hline$\sigma_{0.2}, \mathrm{MPa}$ & $1140 / 1180$ & $2250 / 2350$ \\
\hline$\delta, \%$ & $60 / 60.3$ & $5.9 / 6.0$ \\
\hline$G, \mathrm{GPa}$ & $75 / 71$ & $87 / 85$ \\
\hline \multicolumn{3}{|c|}{ Tests in $3.5 \% \mathrm{NaCl}$ aqueous solution } \\
\hline$\sigma_{\mathrm{u}}, \mathrm{MPa}$ & $-/ 2210$ & $-/ 2450$ \\
\hline$\sigma_{0.2}, \mathrm{MPa}$ & $-/ 1130$ & $-/ 2000$ \\
\hline$\delta, \%$ & $-/ 55.5$ & $-/ 3.5$ \\
\hline$G, \mathrm{GPa}$ & $-/ 67$ & $-/ 64$ \\
\hline$\Delta \sigma_{\mathrm{u}} / \sigma_{\mathrm{u}}, \%$ & $-/ 4.7$ & $-/ 8.6$ \\
\hline
\end{tabular}

of the formation of the structural state giving a set of high physicomechanical and chemical properties of $\mathrm{Cr}-\mathrm{Mn}-\mathrm{N}$ steels are of scientific and practical interest. The aim of this work is to study the effect of the combined thermoplastic treatment, including CPD, on the mechanical and corrosion properties of austenitic $\mathrm{Cr}-\mathrm{Mn}-\mathrm{N}$ steel and their correlation with the steel structure.

\section{EXPERIMENTAL}

We studied commercial austenitic corrosion-resistant 07Kh16AG13M3 steel (chemical composition (wt \%): $0.07 \mathrm{C}, 0.71 \mathrm{Si}, 12.76 \mathrm{Mn}, 16.16 \mathrm{Cr}, 0.11 \mathrm{Ni}$, $3.24 \mathrm{Mo}, 0.82 \mathrm{~N}, 0.05 \mathrm{~V}, 0.015 \mathrm{P}, 0.007 \mathrm{~S}$, and Fe for balance) melted by electroslag remelting under nitrogen pressure $[10,11]$. The initial treatment (IT) was hot plastic deformation by rolling at $1220-1200^{\circ} \mathrm{C}$ followed by recrystallization annealing at $1150^{\circ} \mathrm{C}$ for $1 \mathrm{~h}$ and water quenching. Then, we carried out combined hardening treatment using CPD by rolling in passes of various cross sections using several technological schemes. As a result, we performed CPD of the quenched steel (in what follows, IT + CPD regimes) with the true strain $e=0.2,0.4$, and 0.8 and CPD of the quenched steel with subsequent aging at 500 and $800^{\circ} \mathrm{C}$ (IT $+\mathrm{CPD}+$ Aging regimes). ${ }^{1}$

Static tests of the mechanical properties and SCC tests were performed by the scheme of concentrated bending on an universal TiniusOlsenH50K-S machine; in the tests, we used prismatic $10 \times 10 \times 55-\mathrm{mm}$ speci-

\footnotetext{
${ }^{1}$ The true degree of deformation was estimated by formula $e_{i}=$ $\ln \left(F_{0} / F_{i}\right)$, where $F_{0}$ and $F_{i}$ are the initial (before deformation) and final (after appropriate degree of deformation) cross-sectional areas of the sample.
}

mens with a V-shaped notch. This method of tests was chosen because it has a softer loading scheme than that of tensile tests, which makes it possible to estimate the degree of embrittlement of materials depending on their treatment. The hardness was found on a Rockwell instrument using a diamond cone at a load of 1470 N. Pitting corrosion was studied by a standard method [13] on a VoltaLab 10-PGZ100 device with the VoltaMaster 4 software in a $3.5 \% \mathrm{NaCl}$ aqueous solution at room temperature in an electrochemical cell with a chlorine-silver reference electrode. Steel structure was studied in an EMV-100L transmission electron microscope using the electronograph mode to obtain ring electron diffraction patterns. Phase composition and austenite line components were studied on a DRON-3 diffractometer with $\mathrm{CoK} \alpha$ radiation.

\section{RESULTS AND DISCUSSION}

According to the studies performed in [14], 07Kh16AG13M3 steel has a high (for austenite materials) strength in combination with a high plasticity and a small precipitation hardening effect accompanied by an increase in the yield strength by $30 \mathrm{MPa}$ after holding at $500^{\circ} \mathrm{C}$ for $2 \mathrm{~h}$ as compared to that of the quenched state. It was shown in [14] that a stable passive state without the formation of pittings during the electrochemical polarization of the steel to a potential of $1.4 \mathrm{~V}$ is achieved after quenching and aging at $500^{\circ} \mathrm{C}$. In addition, both insignificant effect of hardening and the conservation of high stability to pitting corrosion after the noted HT are due to a high stability of the $\gamma$ solid solution, which is not accompanied by the $\gamma \rightarrow \alpha^{\prime}$ and $\gamma \rightarrow \varepsilon$ martensite transformations or the precipitation of excess phases during the used hardening HT by quenching and aging.

As an extension of those studies, in this work, we performed mechanical tests of 07Kh16AG13M3 steel during concentrated bending after hardening heat and thermoplastic treatments (Table 1). It is shown that, at a standard test rate $\left(v_{\mathrm{d}}=1.5 \times 10^{-3} \mathrm{~s}^{-1}\right)$, CPD almost doubles the yield strength and the shear modulus of the steel; in this case, the fracture mechanism is changed from a combined to a brittle mechanism. The tests of the steel at a lower strain rate $\left(0.15 \times 10^{-3} \mathrm{~s}^{-1}\right)$ show some hardening of a quenched specimen and an insignificant decrease in its shear modulus, which are similar to those observed in the deformed specimen. According to [2], the embrittlement of nitrogen steels occurs due to intense local plastic deformation provided by a short-range atomic order, which is the structural element of the ordered $\gamma^{\prime} \mathrm{Fe}_{4} \mathrm{~N}$ phase $[2,15]$. The ability of nitrogen atoms to accompany dislocations leads to a local decrease in the shear modulus in the vicinity of dislocations, an increase in their mobility in isolated slip planes, and early submicrocrack nucleation [2]. It was also noted that hydrogen embrittlement has the same nature, when hydrogen atoms accompany dislocations in certain temperature and 

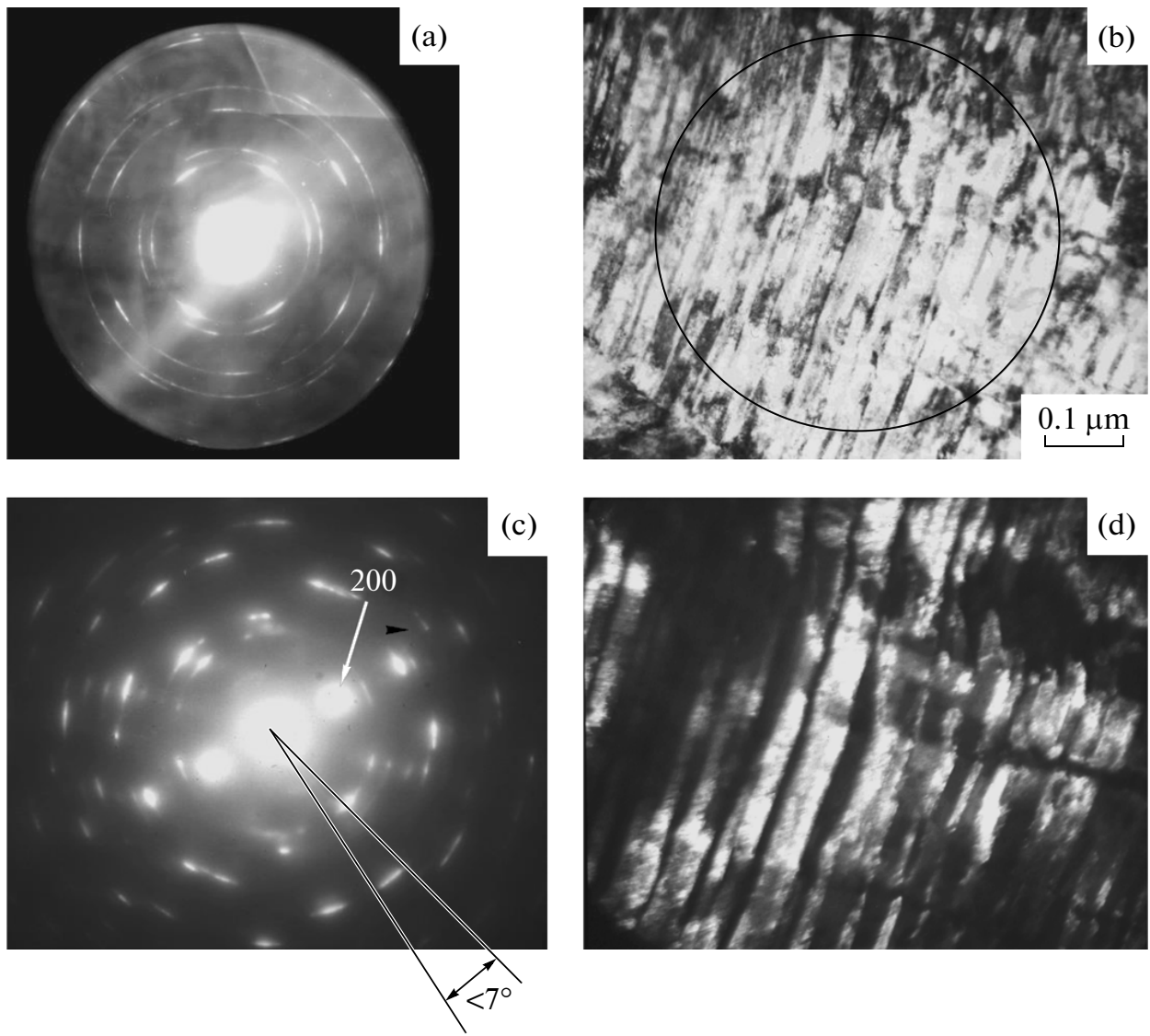

Fig. 1. Fine austenite structure of $07 \mathrm{Kh} 16 \mathrm{AG} 13 \mathrm{M} 3$ steel after the IT + CPD $(e=0.2)$ treatment: (a) ring electron diffraction pattern measured in the electronograph mode, (b) deformation twins and high dislocation density, (c) microdiffraction of a selected structure region, and (d) dark-field image taken with the 111 reflection of austenite.

strain rate ranges, which leads to deformation localization.

The tests of the steel at a low strain rate in a $3.5 \% \mathrm{NaCl}$ aqueous solution demonstrate a weak effect of hydrogen embrittlement, because hydrogen is adsorbed from the electrolyte aqueous solution during its dissociation [16]. As a whole, the embrittlement effect $\left(\Delta \sigma_{u} / \sigma_{u}\right)$ of the quenched 07Kh16AG13M3 steel under the action of the corrosion medium was $4.7 \%$, which demonstrates a high resistance of the steel to SCC as compared to $\mathrm{Cr}-\mathrm{N}$ and $\mathrm{Cr}-\mathrm{Ni}-\mathrm{N}$ steels [9]. The influence of the medium in the deformed steel increased to $8.6 \%$, which is comparable to the best $\mathrm{Cr}-\mathrm{Ni}-\mathrm{Mn}-\mathrm{N}$ austenitic steels during SCC tests [6].

The electron microscopy studies of the 07Kh16AG13M3 steel structure after IT + CPD tests at $e=0.2$ show that the ring electron diffraction pattern contains only austenite lines in the form of symmetrically discontinued rings indicating the formation of a texture (Fig. 1a). We note a high dislocation density and structure fragmentation with a fragment misorientation no higher than $5^{\circ}-7^{\circ}$; the misorientation manifests itself as a radial broadening of the reflections in the electron diffraction pattern (Fig. 1c). The main feature of the steel structure shown in Fig. 1b is a high density of deformation twins, which form in austenite grains predominantly along the $\{200\}$ twinning plane (Fig. 1d).

An increase in the degree of deformation to $e=0.8$ leads to a change in the austenite structure (Fig. 2). The dislocation density is still higher and the fragment misorientation angle increases (on average, it is $\sim 15^{\circ}$ (Fig. 2d). As a result of the increase in the number of the twinning systems (Fig. 2b), the ring electron diffraction pattern demonstrates smeared texture (Fig. 2a). In the places of twin intersection, individual $\alpha$-martensite crystals form (Fig. 2c). The structure contains deformation martensite: there are weak reflections of the bcc phase in the electron diffraction pattern (Fig. 2d).

Twinning and texture smearing are also observed (Figs. 3a, 3b, 3d) in the 07Kh16AG13M3 steel after treatment by the scheme IT + CPD $(e=0.2)+$ Aging $\left(500^{\circ} \mathrm{C}\right)$. It is likely that heating to initiate chromium atom diffusion into the ordered zones of a $\gamma$ ' solid solution with a higher nitrogen content and the formation of the intermediate fcc $\mathrm{CrN}$ phase, which are observed as corresponding blured reflections in the electron diffraction pattern (Fig. 3c). 

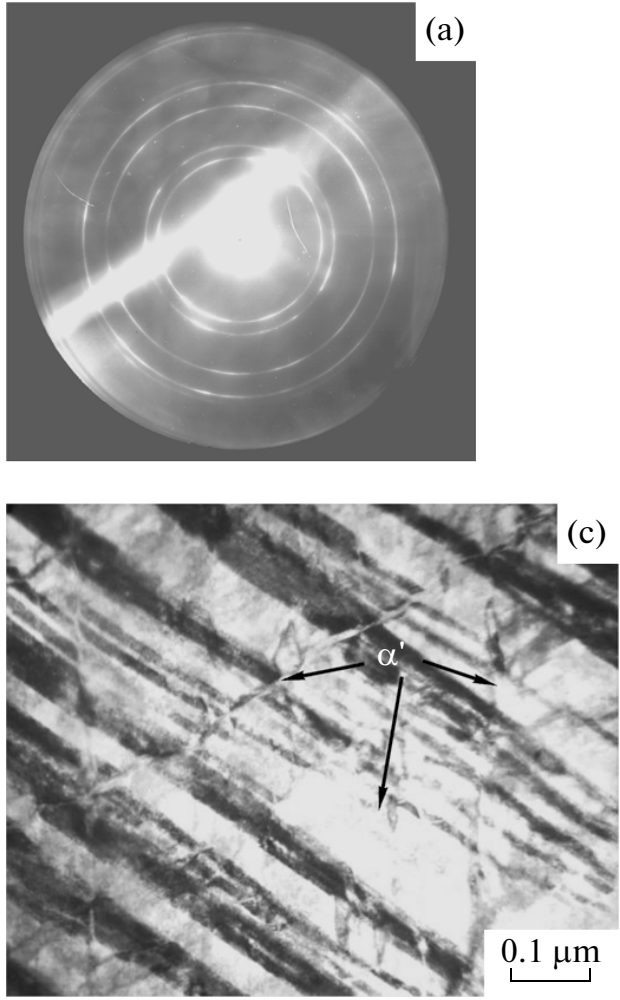
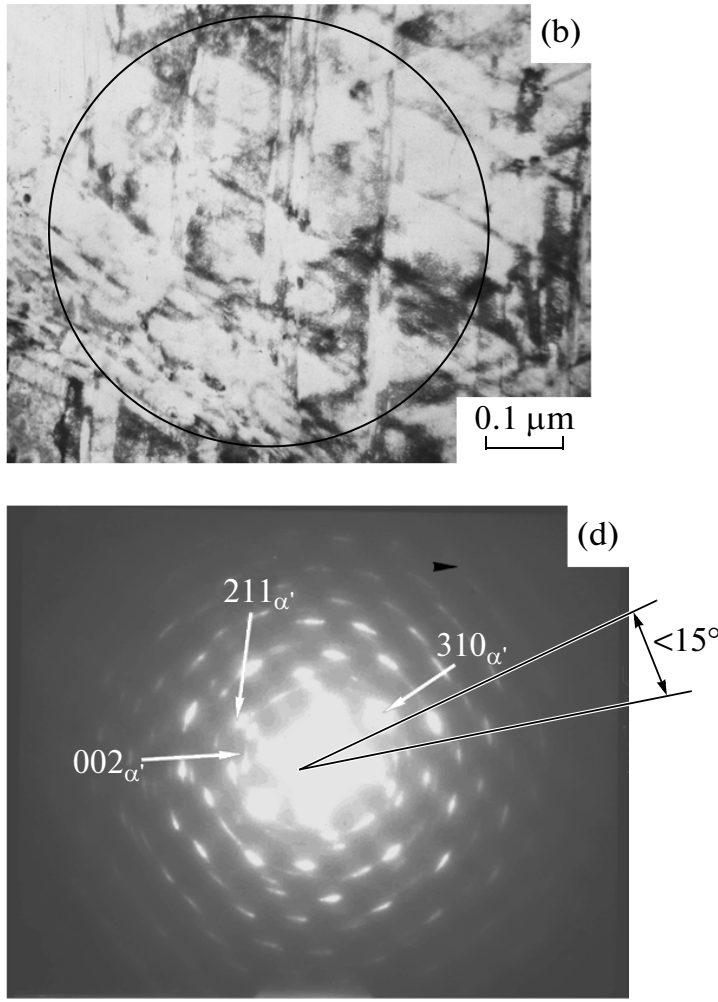

Fig. 2. Fine austenite structure of $07 \mathrm{Kh} 16 \mathrm{AG} 13 \mathrm{M} 3$ steel after the IT + CPD $(e=0.8)$ treatment: (a) ring electron diffraction pattern, (b) deformation twins, (c) formation of deformation $\alpha^{\prime}$ martensite, and (d) microdiffraction of a selected structure region with martensite reflections.
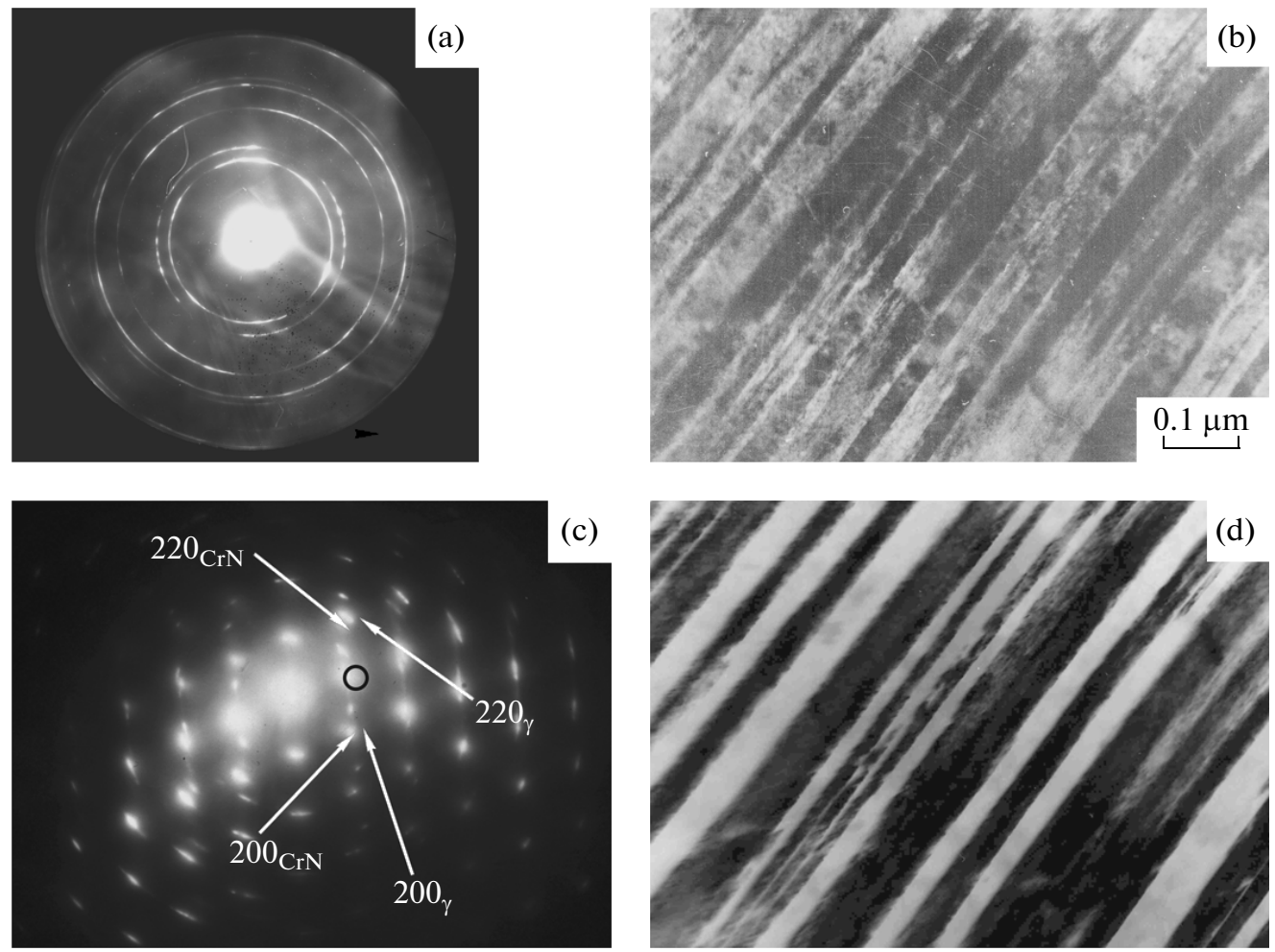

Fig. 3. Fine austenite structure of $07 \mathrm{Kh} 16 \mathrm{AG} 13 \mathrm{M} 3$ steel after the IT $+\mathrm{CPD}(e=0.2)+$ Aging $\left(500^{\circ} \mathrm{C}\right)$ treatment: (a) ring electron diffraction pattern, (b) austenite twinning, (c) microdiffraction pattern of a selected structure region with reflections of the ordered CrN phase, and (d) dark-field image in the 111 reflection of austenite. 

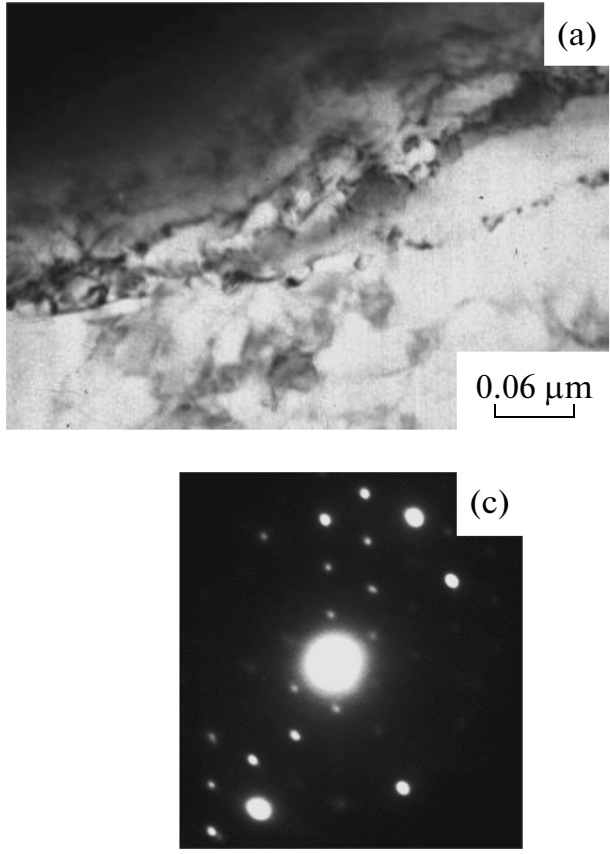

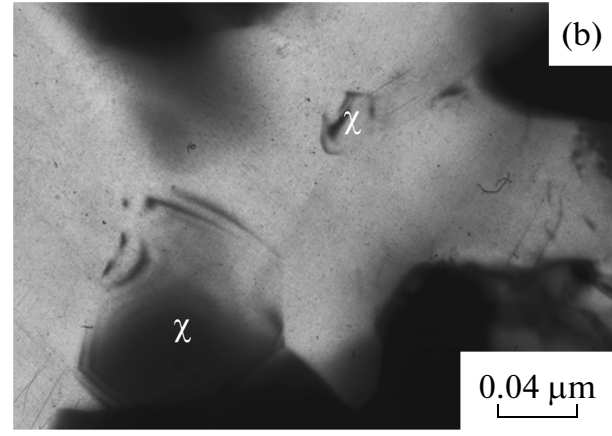

(d)

Fig. 4. Fine austenite structure of $07 \mathrm{Kh} 16 \mathrm{AG} 13 \mathrm{M} 3$ steel after the IT $+\mathrm{CPD}+$ Aging at $800^{\circ} \mathrm{C}$ treatment: (a, b) excess phase precipitates along austenite grain boundaries; $(c, d)$ electron diffraction pattern of the precipitated phase and the key pattern, respectively.

The electron microscopy study of the steel aged at $800^{\circ} \mathrm{C}$ shows that the low pitting corrosion resistance of the steel is caused by excess-phase precipitates along grain boundaries (Figs. 4a, 4b). An analysis of the electron diffraction pattern of the precipitated phase (Figs. 4c, 4d) made it possible to identify it as the intermetallic $\chi$ phase of the $\mathrm{Fe}_{36} \mathrm{Cr}_{12} \mathrm{Mo}_{10}$ type having an ordered cubic lattice with parameter $a=$ $0.8852 \mathrm{~nm}$, which agrees with [17].

In this work, we also measured the hardness and estimated the components of the physical broadening of the austenite lines of the 07Kh16AG13M3 steel after the treatments under study. It is shown that the treatment by IT + CPD $(e=0.2)$ scheme doubles the hardness of the specimens compared to that of the initial structural state (Fig. 5a). According to the X-ray diffraction studies of the physical broadening of the austenite lines as a function of the degree of CPD (Fig. 5b), coherent domain (block) size $D$ increases from 40 to $210 \mathrm{~nm}$ when the deformation degree increases from 0.2 to 0.4 , and this fact can be related to transverse slip processes. A further increase in the deformation degree to 0.8 leads to the refining of blocks to $140 \mathrm{~nm}$ due to the formation of a cellular structure of dislocations with exhausted slip systems and developed dynamic recovery processes. The microdistortions of the austenite crystal lattice monotonically increase with the degree of CPD, which agrees well with a similar dependence for hardness and leads to the conclusion that the crystal lattice microdistortions play a key role in steel hardening.
Using the approximation method [18, 19], we estimated the contribution of each structural defect parameter to the broadening of the diffraction. In the case where there are only microdistortions in the steel at a block size $D>150 \mathrm{~nm}$, the ratio of the broadenings of the lines of different reflection orders from crystallographic plane $\{111\}$ is $\beta_{222} / \beta_{111}=\tan \theta_{222} / \tan \theta_{111}$. When there are no distortions and the block size is small $(D<150 \mathrm{~nm})$, the entire line broadening is due to the dispersion of blocks, and we have $\beta_{222} / \beta_{111}=$ $\cos \theta_{222} / \cos \theta_{111}$. From an analysis of the physical broadening of austenite lines and a comparison with tangents and cosines of the corresponding Bragg angles, we found the range in which the line broadening is caused by the existence of microdistortions and blocks, $1.75<\beta_{222} / \beta_{111}<3.52$. Based on a comparison of the calculated data with the data noted above (Table 2), we conclude that the austenite line broadening is due to the size of a block structure after deformation at $e=$ 0.2 and due to microdistortions at $e=0.4$, and both

Table 2. Relative physical broadening $\beta_{222} / \beta_{111}$ of the austenite lines of $07 \mathrm{Kh} 16 \mathrm{AG} 13 \mathrm{M} 3$ steel after CPD by rolling

\begin{tabular}{c|c|l}
\hline$e$ & $\beta_{222} / \beta_{111}$ & $\begin{array}{c}\text { Main factor of the physical } \\
\text { broadening of the austenite lines }\end{array}$ \\
\hline 0.2 & 2.40 & Blocks \\
0.4 & 3.25 & Microdistortions \\
0.8 & 3.14 & Microdistortions and blocks \\
\hline
\end{tabular}



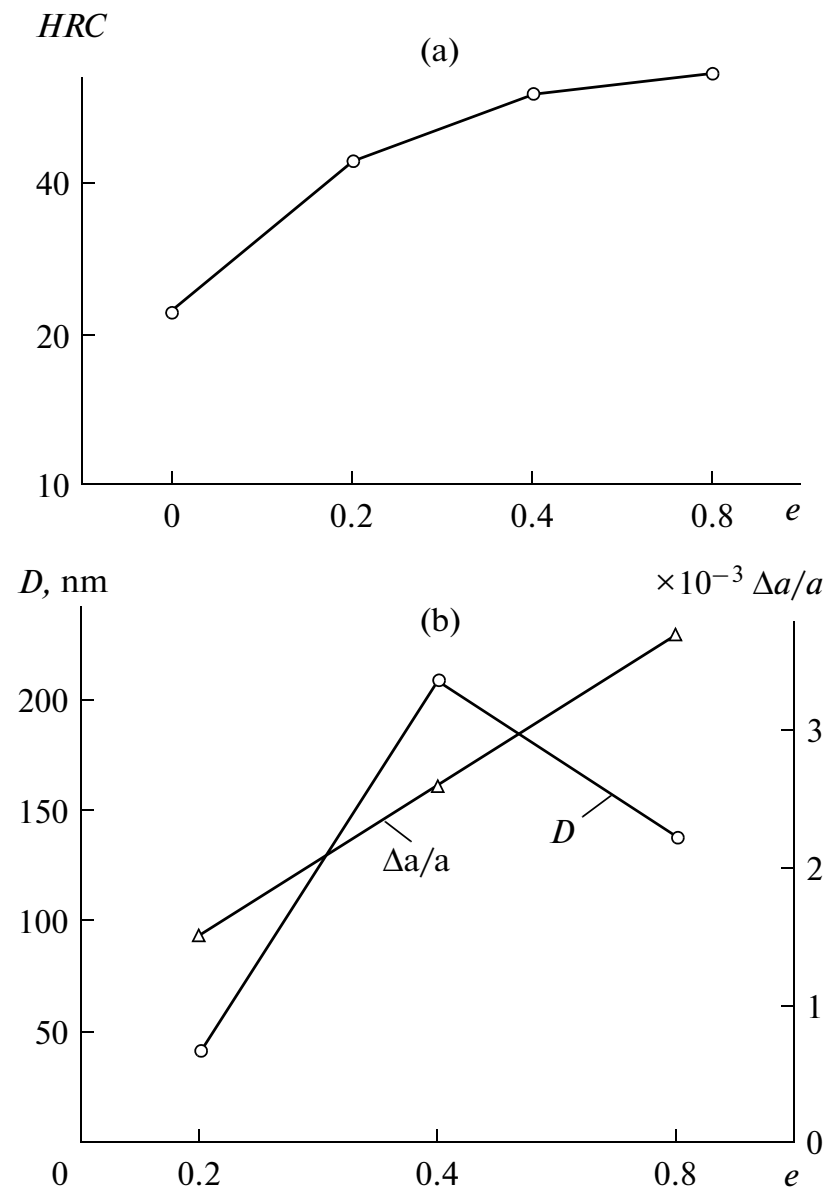

Fig. 5. Dependences of (a) hardness and (b) physical broadening $\Delta a / a$ of austenite lines and coherent domain size $D$ in $07 \mathrm{Kh} 16 \mathrm{AG} 13 \mathrm{M} 3$ steel on the true CPD strain.

factors (among them the latter is dominant) contribute to the line broadening at $e=0.8$.

The electrochemical studies of the influence of CPD on the pitting corrosion resistance of 07Kh16AG13M3 steel show that, at all degrees of deformation $(e=0.2$, $0.4,0.8)$ and also after aging at $500^{\circ} \mathrm{C}$ by the scheme IT + CPD + Aging, all pitting corrosion curves almost coincide without violation of the passive state of steel up to potentials $E_{\mathrm{p}}=1.35-1.40 \mathrm{~V}$ (Fig. 6a), as in the case after aging of the quenched steel at $500^{\circ} \mathrm{C}$ for $2 \mathrm{~h}$ [14]. This value of potential $E_{\mathrm{p}}$ corresponds to that obtained in [20] for manganese-free steels containing $0.9-1.1 \% \mathrm{~N}$ and $18 \% \mathrm{Cr}$ and tested under the same conditions. It should be noted that the pitting corrosion curves of the 07Kh16AG13M3 steel specimens aged at $500^{\circ} \mathrm{C}$ after deformation, unlike those of the specimens aged after quenching, have two pitting formation potentials corresponding to a corrosion current density $j=0.02 \mathrm{~mA} / \mathrm{cm}^{2}[14]: E_{\mathrm{p} 2}=1.35 \mathrm{~V}$ is the potential of the initial $\gamma$ solid solution and $E_{\mathrm{p} 1}=1.00 \mathrm{~V}$ is the potential of the $\gamma$ solid solution depleted of chro- $j, \mathrm{~mA} / \mathrm{cm}^{2}$

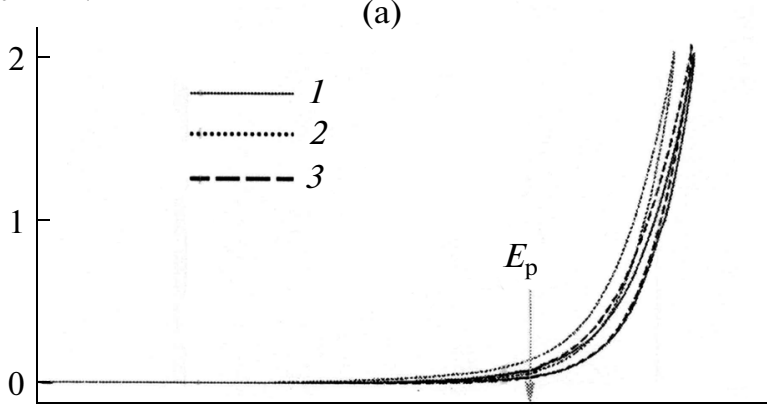

(b)

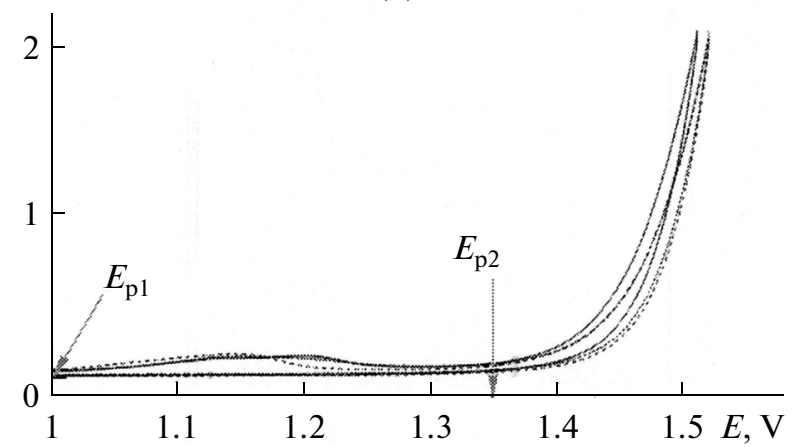

$j, \mathrm{~mA} / \mathrm{cm}^{2}$

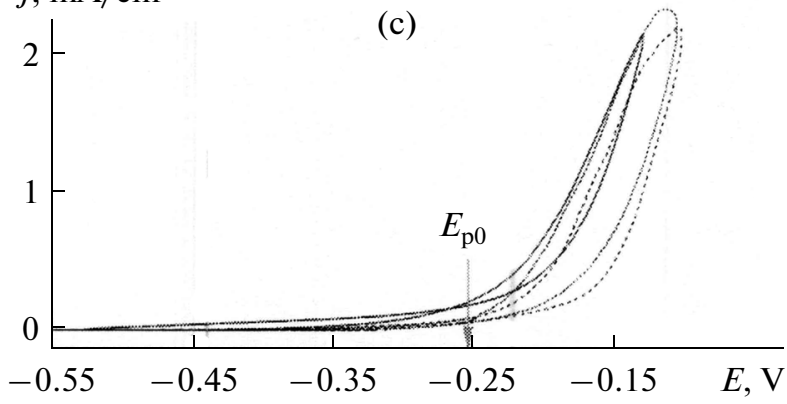

Fig. 6. Pitting corrosion of $07 \mathrm{Kh} 16 \mathrm{AG} 13 \mathrm{M} 3$ steel after treatment at various true deformation degrees $(e=(1) 0.2$, (2) 0.4 , (3) 0.8 ) performed according to the following schemes: (a) IT + CPD, (b) IT + CPD + Aging $\left(500^{\circ} \mathrm{C}\right)$, and (c) IT + CPD + Aging $\left(800^{\circ} \mathrm{C}\right)$.

mium and nitrogen because of the formation of the intermediate $\mathrm{CrN}$ phase due to chromium separation (Fig. 6b).

Figure 6c depicts the pitting corrosion of 07Kh16AG13M3 steel as a function of the degree of CPD during combined treatment according to the same scheme IT $+\mathrm{CPD}+$ Aging $\left(800^{\circ} \mathrm{C}, 2 \mathrm{~h}\right)$. Unlike the case of aging at $500^{\circ} \mathrm{C}$, the pitting corrosion resistance decreases significantly, which is expressed in a potential $E_{\mathrm{p}}$ shift to $-0.25 \mathrm{~V}$. A higher pitting formation activity of the steel in this structural state is related to the precipitation of the $\chi$ phase enriched in molybdenum and chromium along austenite grain boundaries. 


\section{CONCLUSIONS}

(1) High-nitrogen austenite 07Kh16AG13M3 steel has a high strength and plasticity properties $\left(\sigma_{0.2}=\right.$ $1140 \mathrm{MPa}, \delta \geq 60 \%$ ) during concentrated bending tests and is effectively hardened during cold plastic deformation (CPD) by rolling in passes, conserving a certain plasticity margin after deformation at $e=0.2$ $\left(\sigma_{0.2}=2250 \mathrm{MPa}, \delta=6 \%\right)$.

(2) It is shown that the shear in the austenite crystal lattice of the steel during CPD occurs by slip ad twinning. However, the twinning process developing along several shear systems makes the main contribution to an increase in the steel plasticity.

(3) Electron microscopy shows that austenite in the steel is highly resistant to martensitic transformations during CPD rolling at $e=0.2$ and 0.4 , while high degrees of deformation $(e=0.8)$ lead to the formation of individual $\alpha^{\prime}$ martensite crystals at their intersection sites. Aging at $500^{\circ} \mathrm{C}$ initiates the formation of the intermediate ordered $\mathrm{CrN}$ phase having an ordered fcc lattice.

(4) The steel hardness correlates well with the austenite lattice microdistortions in the steel, which monotonically increase with the degree of CPD. In this case, the coherent domain size has a maximum $(210 \mathrm{~nm})$ at $e=0.4$, which corresponds to the stage of dynamic recovery.

(5) The contribution of the structure imperfection parameters of the steel to the physical broadening of the austenite lines was estimated by X-ray diffraction: the broadening is mainly due to the coherent domain size at $e=0.2$, the microdistortions at $e=0.4$, and both factors at $e=0.8$.

(6) The steel subjected to combined hardening treatment according to the schemes IT + CPD and IT + CPD + Aging at $500^{\circ} \mathrm{C}$ is stably passive up to a polarization potential $E_{\mathrm{p}}=1.35-1.4 \mathrm{~V}$ and is not prone to pitting corrosion in artificial see water. In addition, the steel loss of strength due to SCC after treatment by the scheme IT $+\mathrm{CPD}$ at $e=0.2$ was only $8.6 \%$ relative to tests in air.

(7) The state of the deformed steel aged at $500^{\circ} \mathrm{C}$ is characterized by the appearance of a low corrosion current maximum due to the formation of an intermediate CrN-type phase almost without changing the pitting formation potential $\left(E_{\mathrm{p}}=1.35 \mathrm{~V}\right)$, while aging at $800^{\circ} \mathrm{C}$ leads to a substantial decrease in the pitting formation potential to $-0.25 \mathrm{~V}$ due to the decomposition of a supersaturated $\gamma$-solid solution with the formation of the $\chi$ phase along austenite grain boundaries.

(8) Based on these results, the optimal structural state of the $07 \mathrm{Kh} 16 \mathrm{AG} 13 \mathrm{M} 3$ steel that forms as a result of combined hardening treatment by the scheme IT + CPD $(e \leq 0.4)$ and determines the set of high mechanical $\left(\sigma_{0.2}=2250 \mathrm{MPa}, \delta=6 \%, G=87 \mathrm{GPa}\right)$ and corrosion $\left(E_{\mathrm{p}} \simeq 1.4 \mathrm{~V}, \Delta \sigma_{\mathrm{u}} / \sigma_{\mathrm{u}}=8.6 \%\right)$ properties is thought to be an austenite structure with a high density of deformation twins that is resistant to the formation of the ordered intermediate $\mathrm{CrN}$ phase and the $\alpha^{\prime}$ deformation martensite.

\section{ACKNOWLEDGMENTS}

The authors are grateful to L.D. Chumakova for the assistance in performing the experiment.

This work is supported by the Russian Foundation for Basic Research, project no. 11-03-00065-a.

\section{REFERENCES}

1. V. Gavriljuk and H. Berns, High Nitrogen Steels (Springer, Berlin, 1999).

2. V. G. Gavriljuk, "Physical foundations of nitrogen steels," in Promising Materials: Structure and Investigation Methods (TGU, Tol'yatti, 2007), pp. 5-74.

3. H. J. C. Speidel and M. O. Speidel, "Nickel and chromium based high nitrogen alloys," in HNS 2003 (High Nitrogen Steels), Ed. by M. O. Markus, C. Kowanda, and M. Diener (Swiss Federal Inst. Technol., Zurich, 2003), pp. 101-112.

4. H. Berns, "Stickstoffmartensit, grundlage und anwendung," HNM: Harter--Techn., Mitt. 55 (1), 8-14 (2000).

5. O.A. Bannykh, V. M. Blinov, V. V. Berezovskaya, M. V. Kostina, M. A. Gervas'ev, I. V. Golyakov, and I. S. Trushin, "Effect of $\gamma \rightarrow \alpha$ martensitic transformation in $\mathrm{Fe}-\mathrm{Cr}-\mathrm{N}$ alloys on the stress corrosion cracking,” Russian Metallurgy (Metally), No. 4, 310-314 (2005).

6. V. V. Berezovskaya, "The alloying system of high-nitrogen austenite steels, the structure, mechanical properties, and corrosion properties," in Proceedings of I International Interactive Scientific-Engineering Conference on Innovations in Materials Science and Metallurgy (Ural'skii Universitet, Yekaterinburg, 2012), pp. 257-266.

7. M. O. Speidel, "New nitrogen-containing austenite stainless steels with high strength and plasticity," Metalloved. Term. Obrab. Met., No. 11, 9-14 (2005).

8. V. V. Berezovskaya, T. G. Lobanova, and I. A. Krutikova, "Effect of the hardening technology on the structure, properties, and SCC resistance of high-strength bandage steels," in Proceeding of XVII St. Petersburg Readings on the Problems of the Strength Devoted to 90th Jubilee of Prof. A.N. Orlov (SPbGU, St. Petersburg, 2007), pp. 166-168.

9. V. V. Berezovskaya, "Effect of thermo-plastic treatment on structure and corrosion properties of high nitrogen Cr-steels," J. Met. Eng. 2 (1), 19-28 (2013).

10. G. Stein and I. Hucklenbroich, "Manufacturing and application of high nitrogen steels," in HNS 2003 (High Nitrogen Steels), Ed. by M. O. Markus, S. Kowanda, and M. Diener (Swiss Federal Inst. Technol., Zürich, 2003), pp. 21-30.

11. R. Ritzenhoff, "Manufacturing of HNS alloys at Energietechnik Essen Gmbh-a process overview," 
in Proceedings of 10th International Conference on High Nitrogen Steels (MISiS, Moscow, 2009), pp. 243-248.

12. State Standard GOST 9.901.1-89. General Requirements for the Methods of Corrosion Cracking Tests (Izd-vo Standartov, Moscow, 1999).

13. State Standard GOST 9.912.-89. Methods of Accelerated Pitting Corrosion Resistance Tests (Izd-vo Standartov, Moscow, 1993).

14. V. V. Berezovskaya, R. A. Savrai, E. A. Merkushkin, and V. A. Makarov, "Structure, mechanical and corrosion properties of new high-nitrogen $\mathrm{Cr}-\mathrm{Mn}$ steels containing molybdenum," Russian Metallurgy (Metally), No. 5, 380-388 (2012).

15. A. J. Bottger, D. E. Nanu, and A. Marashdeh, "Orderdisorder transitions in high nitrogen steels: from ab-initio to statistical thermodynamics," in Proceedings of 10th International Conference on High Nitrogen Steels (MISiS, Moscow, 2009), pp. 31-34.

16. V. V. Berezovskaya, "On the nature of high sensitivity of $\mathrm{Fe}-\mathrm{Ni}$ and $\mathrm{Fe}-\mathrm{Ni}-\mathrm{Co}$ maraging steels with titanium to delayed failure," Russian Metallurgy (Metally), No. 5, 419-428 (2003).

17. O. A. Bannykh, P. B. Budberg, S. P. Alisova, et al., Phase Diagrams of Binary and Multicomponent $\mathrm{Fe}$ Based Systems: A Handbook (Metallurgiya, Moscow, 1986).

18. S. S. Gorelik, L. N. Rastorguev, and Yu. A. Skakov, $X$-ray Diffraction and Electron-Optical Analysis (Metallurgiya, Moscow, 1970).

19. Ya. S. Umanskii, Yu. A. Skakov, A. N. Ivanov, and L. N. Rastorguev, Crystallography, X-ray Diffraction, and Electron Microscopy (Metallurgiya, Moscow, 1982).

20. S. J. Mushnikova, M. V. Kostina, Ch. A. Andreev, and L. Ts. Zhekova, "Effect of the structure and phase composition on the pitting corrosion resistance of the $\mathrm{Cr}-\mathrm{N}$ steels with overequilibrium nitrogen content," in Proceedings of 10th International Conference on High Nitrogen Steels (MISiS, Moscow, 2009), pp. 300-305.

Translated by Yu. Ryzhkov 